\title{
SE NOSSOS FILHOS ESTUDAREM, SERÃO GENTE NA VIDA?
}

IF OUR CHILDREN STUDY, WILL THEY BE 'SOMEONE' IN LIFE?

SI NUESTROS HIJOS ESTUDIAN, ¿SERÁN 'ALGUIÉN' EN LA VIDA?

\author{
BASNIAK, Maria Ivete 1 \\ ALMEIDA, Antonio Charles Santiago de ${ }^{2}$
}

\section{RESUMO}

Este trabalho discute como as famílias de alunos das classes menos favorecidas significam o papel da escola na formação de seus filhos e suas expectativas de ascensão social. Para tal utiliza pesquisa qualitativa permeada pela subjetividade do cotidiano, mas capaz de identificar e analisar dados que estão para além da mensuração. Assim, buscou-se correspondência entre conceitos bourdieusianos e expressões de famílias, coletadas por meio de videogravações de entrevistas semiestruturadas em uma realidade específica. O principal resultado pesquisa evidencia-se pela crença que as entrevistadas depositam na escola, como lugar de privilégio, onde se pode ascender socialmente.

Palavras-chave: Conservação. Reprodução. Escola.

\section{ABSTRACT}

This paper discusses how students' families from the underprivileged classes are the result of the role played by the school and their expectations about social promotion. For this it uses a qualitative research impregnated by everyday life subjectivity, but at the same time, it can identify and analyze data beyond measurement. We looked for a relation between Bourdieusian concepts and expressions used by the families, collected through videorecording, semi-structured interviews in a specific reality. The main result of our research is upheld by the belief that the interviewed has on the school as a place of privilege, where a social promotion is possible.

Keywords: Conservation. Reproduction. School.

\section{RESUMEN}

Este trabajo discute cómo familias de alumnos de las clases menos favorecidas son el resultado del papel jugado por la escuela en la formación de sus hijos y las expectativas sobre el ascenso social. Se usa una investigación cualitativa impregnada por la subjetividad del día a día, pero al mismo tiempo es capaz de identificar y analizar datos más allá de la medición. Se buscó relacionar conceptos bourdieusianos con las expresiones utilizadas por las familias, a través de videograbaciones de entrevistas semiestructuradas en una realidad específica. El principal resultado de la investigación se sustenta por la confianza que las entrevistadas depositan en la escuela como lugar de privilegio, donde se puede ascender socialmente.

Palabras clave: Conservación. Reproducción. Escuela.

\footnotetext{
${ }^{1}$ Universidade Estadual do Paraná, UNESPAR - Brasil.

2 Universidade Estadual do Paraná, UNESPAR - Brasil.
} 


\section{INTRODUÇÃO}

Ao pensarmos sobre o papel da educação e seu reflexo na escola, e ainda sobre sua influência na sociedade atual, diferentes opiniões, esperanças, culpas, anseios, crenças e promessas são lançadas sobre o debate emergente nos diversos meios, inclusive dentro do ambiente escolar.

Ao ingressar na escola, muitos alunos, principalmente aqueles das camadas menos favorecidas, depositam nela a esperança de um futuro melhor, com acesso a novas oportunidades e que Ihes permita ascender na sociedade. Essas expectativas têm fruto na família, que tende a transferir e depositar no filho que inicia a jornada escolar - a qual espera sempre que dure mais que a do filho anterior - a esperança de que possa ter um futuro melhor do que o seu. Na prática, isso dificilmente se concretiza. Bourdieu (2003a) destaca que as famílias, ainda que não explicitamente, transmitem a seus filhos valores que colaboram para definir suas atitudes frente à escola, e que ainda que queiram acreditar e impor a seus filhos que a escola é importante meio de ascender social e culturalmente, implicitamente, sabem que isso não é o que se efetiva. Isso evidencia que, infelizmente, vivenciamos cotidianamente uma forte tendência de a escola perpetuar a exclusão de classes e não contribuir para a ascensão daqueles das camadas menos favorecidas da população. Assim, muitos daqueles que depositam alguma esperança de mudança na escola, internamente, bem o sabem que a escola tende a ser mais um fator de exclusão. Isto se manifesta em expressões comumente utilizadas por aqueles em situação de vulnerabilidade ao bandonar a escola, como, por exemplo, isso não é para nós. $\mathrm{Na}$ verdade, dizem mais do que isso, significa: "não temos meios para isso" (BOURDIEU, 2003a, p. 47). Expressão da necessidade interiorizada, essa declaração está no imperativo-indicativo, pois exprime, ao mesmo tempo, impossibilidade e interdição. Isso porque "[...] o desejo razoável de ascensão através da escola não pode existir enquanto as chances objetivas de êxito forem ínfimas [...]" (BOURDIEU, 2003a, p. 48). Neste trabalho, discutimos brevemente a realidade de famílias de alunos em situação de vulnerabilidade econômica e social de uma escola pública, as quais foram entrevistadas pelos bolsistas do subprojeto de Matemática do Pibid de uma universidade pública paranaense. As entrevistas tiveram duplo sentido: por um lado, possibilitar que os alunos bolsistas do Pibid conhecessem de perto a realidade de alguns alunos de uma das escolas em que atuavam com o subprojeto; e por outro, perceber como as famílias desses alunos significam o papel da escola na formação de seus filhos e suas expectativas de ascensão social. O primeiro item não será discutido neste trabalho. Preocupamonos com o segundo ponto estabelecido: discutir como as famílias de alunos das classes menos favorecidas significam o papel da escola na formação de seus filhos e suas expectativas de ascensão social. Para isto, tomamos como base teórica o expediente bourdieusiano da escola como espaço de conservação social, o qual é explicitado na seção que segue.

\section{FUNÇÃO DA ESCOLA: EXCERTOS DE BOURDIEU}

Para Bourdieu (2003a, p.42), a "herança cultural, que difere, sob dois aspectos, segundo as classes sociais, é a responsável pela diferença inicial das crianças diante da experiência escolar e, consequentemente, pelas taxas de êxito". Entretanto, essa seleção dos alunos, já nos primeiros meses 
de escolarização, não é de forma alguma explicitada pela escola, que se defende perante a exclusão que produz sob a alegação de que, ainda que ofereça as melhores condições, o problema está nos seus alunos que não conseguem obter desempenho escolar satisfatório. Assim, embora seja uma instituição social constituída, a escola utiliza artifícios da seleção natural para defender suas fragilidades. Bourdieu e Passeron (1975, p. 250) destacam que "o que separa a autoeliminação a longo prazo e a eliminação imediata que tem como base uma previsão das oportunidades objetivas de eliminação, é o tempo que é preciso no primeiro caso para que excluídos se persuadam de sua exclusão".

As derrotas escolares vivenciadas pelas famílias menos favorecidas - sejam dos pais, que não conseguiram concluir nem mesmo os anos iniciais do Ensino Fundamental (EF); ou dos que estão próximos à família - faz com que, muitas vezes, aqueles que não conseguem atingir seu objetivo em um primeiro momento, planejem o segundo passo de duas formas distintas: "ele pode situar seu alvo muito baixo, frequentemente aquém de seu êxito passado [...], ou então ele situa seu alvo acima de suas possibilidades" (BOURDIEU, 2003a, p. 49). Assim, as crianças tendem a aceitar sua condição social, passando pela seleção social que a escola faz, como se fossem desprovidos de dons e méritos, ficando convencidos de que, na verdade, eram eles que não queriam a escola e não que foi a escola que os rejeitou (BOURDIEU, 2003b).

Por outro lado, os casos de sucesso que presenciamos, daqueles provenientes de famílias menos favorecidas, fazem parecer que todos podem, de alguma forma, progredir, como se "o sucesso excepcional de alguns indivíduos que escaparam ao destino coletivo dá uma aparência de legitimidade à seleção escolar, e dá crédito ao mito da escola libertadora, junto àqueles próprios indivíduos que ela eliminou [...]" (BOURDIEU, 2003a, p. 59).

Bourdieu (2003a) salienta, também, que as aspirações e ações dos sujeitos são influenciadas pelo grupo a que pertencem e, consequentemente, pelos anseios e objetivos desse grupo. Embora Bourdieu (2003a) descreva a realidade francesa, vemos igualmente a mesma reprodução na realidade brasileira. Os pais e a população em geral também tendem a corroborar tal pressuposto, sem considerar que a escola é, na maioria das vezes, a única forma de acesso do aluno a realidades culturais diferentes da sua. Além disso, todos aqueles que conhecem diferentes escolas sabem que, salvo raras exceções, escolas dos bairros mais pobres tendem a possuir menos infraestrutura do que as escolas dos bairros mais ricos. Sem recursos e infraestrutura, ainda que desejem, os educadores dessas escolas têm inúmeras dificuldades para desenvolver um trabalho condizente com suas necessidades. Isto porque não dispõem, na maioria das vezes, de recursos didáticos e pedagógicos adequados, da formação necessária e suporte de pessoal especializado para auxiliar com as dificuldades e especificidades da diversidade da realidade dos alunos com quem trabalha. Neste contexto, o capital cultural e o ethos, ao se combinarem, concorrem para definir as condutas escolares e as atitudes diante da escola, que constituem o princípio de eliminação diferencial das crianças das diferentes classes sociais.

De acordo com a assertiva acima, a escola tende a ser conservadora da condição social dos indivíduos, sem oferecer possibilidades de ascensão: ao contrário, tende a fazer o próprio indivíduo 
conformar-se com seu lugar na sociedade, acreditando que aquilo não é para ele. A escola, portanto, reproduz o papel do Estado, de manter os indivíduos em seus devidos lugares.

Com isto, o Estado, por meio da escola, garante uma ordem social: conserva uma estrutura de dominação entre os favorecidos e os não favorecidos. Para que os favorecidos sejam mais favorecidos e os desfavorecidos mais desfavorecidos, é "necessário e suficiente que a escola ignore, no âmbito dos conteúdos que transmite, dos métodos e técnicas de transmissão e dos critérios de avaliação, as desigualdades culturais entre as crianças das diferentes classes sociais" (BOURDIEU, 2003a, p. 53). Dessa forma, a escola tende a cumprir o papel de conservadorismo da transmissão cultural, reificando o papel que o Estado Ihe impõe, e tendendo a desvalorizar meios de acesso a conhecimentos que não atendam aos interesses do Estado e não corroborem para esse fim.

Desse modo, enquanto instituição formal de educação, a escola falha ao se propor a atender as diferentes classes sociais, porque tende a excluir cada vez mais os excluídos, fazendo-os crer que aquele não é seu lugar. É sabido que, para Bourdieu, a escola configura-se como o espaço de reprodução das estruturas sociais, bem como de dominação, no que compreende uma lógica social, herdeiros e não herdeiros do sucesso humano. Contudo, este entendimento sociológico não é percebido, sobretudo por aqueles que têm, na escola, a esperança de mudança de suas condições econômicas e sociais e, em diferentes situações, também por aqueles que estão à frente do processo de gestão e ensino nas escolas. Assim, faz-se necessário que educadores, que entendemos como professores, diretores, pedagogos, funcionários de escola e futuros professores, conheçam um pouco da realidade dos alunos com quem trabalham ou trabalharão. O presente trabalho iniciou desse pressuposto, como apresentamos na seção que segue.

\section{CONTEXTO E METODOLOGIA}

As discussões aqui tratadas emergem prinicipalmente de vivências no subprojeto de Matemática do Pibid de uma universidade pública, que se originaram de debates quanto ao desempenho, comprometimento e envolvimento dos alunos da escola na aprendizagem de Matemática. Observações a respeito da participação e do desempenho dos alunos da Educação Básica nas tarefas propostas pelos bolsistas revelavam, em suas falas, a angústia da falta de interesse de alguns alunos em se envolverem e participarem. Ao buscarmos compreender o porquê dessa percepção dos bolsistas, identificamos, em seus discursos, excertos da "ideologia fatalista do discurso e das políticas neoliberais" (FREIRE, 1996, p. 101).

A fim de provocá-los para refletirem quanto ao impacto que o capital cultural e ethos têm no comportamento e desempenho escolar, acordamos que realizaríamos entrevistas com as famílias de alguns alunos de uma das escolas em que atuavam. A escola escolhida foi a que apresentava alunos com maiores dificuldades de aprendizagem, por se encontrarem em situação de vulnerabilidade social. As famílias a serem entrevistadas foram indicadas pela pedagoga da escola, considerando a disponibilidade dos familiares dos alunos, sendo eles de famílias de baixa renda.

A investigação obedeceu aos critérios éticos da pesquisa com serem humanos, os quais foram avaliados por Comitê de Ética e aprovados, segundo o parecer 014/2013. Os nomes são fictícios a fim 
de garantir a confidencialidade dos dados e preservar a identidade dos participantes, garantindo critérios éticos. Foram selecionadas seis famílias para serem entrevistadas, de dois alunos do $6^{\circ}$ ano, Paula e Daniel; dois do $8^{\circ}$ ano, Clara e Ale; e dois alunos do $9^{\circ}$ ano, Luci e Luan. Todos receberam e assinaram o Termo de Consentimento Livre e Esclarecido, que foi lido para que pudessem esclarecer quaisquer dúvidas quanto à pesquisa, deixando claro que poderiam retirar seu consentimento a qualquer momento que desejassem.

O estabelecimento da entrevista como meio de recolha de dados está apoiado em Gil (2010, p. 109), que considera que ela "é bastante adequada para a obtenção de informações acerca do que as pessoas sabem, crêem, esperam, sentem ou desejam, pretendem fazer, fazem ou fizeram".

Neste panorama, professores da universidade e supervisores do Pibid, em meados de 2013, acompanharam os bolsistas até a casa dos alunos e realizaram entrevistas semiestruturadas com os pais ou responsáveis. As entrevistas foram gravadas e transcritas, e entre as falas dos entrevistados, selecionamos excertos de duas delas para explicitar suas visões em nossa discussão neste trabalho, a fim de não tornar o discurso extremamente extenso e redudante.

Então, este artigo constitui uma pesquisa qualitativa, estruturada como investigação de uma determinada realidade, permeada pela subjetividade do cotidiano, mas capaz de identificar e analisar dados que estão para além da mensuração. Em suma, buscamos compreender, em uma realidade específica de uma cidade do interior do estado do Paraná, como as famílias de alunos das classes menos favorecidas significam o papel da escola na formação de seus filhos e suas expectativas de ascensão social, a partir da expressão dessas famílias. Como elementos de análise, buscamos estabelecer correspondência entre os principais conceitos enunciados por Bourdieu, a partir de nosso quadro teórico, com elementos conceituais identificados nas expressões dos entrevistados, como apresentamos no Quadro 1.

\section{Quadro 1 - CORRESPONDÊNCIA ENTRE OS CONCEITOS BOURDIEUSIANOS E AS ENTREVISTAS REALIZADAS}

\begin{tabular}{|l|l|}
\hline \multicolumn{1}{|c|}{ Conceitos Bourdieusianos (CB) } & \multicolumn{1}{c|}{ Correspondência Conceitual (CC) } \\
\hline Herança cultural (HC) & $\begin{array}{l}\text { Herança cultural dos pais influencia o desenvolvimento escolar } \\
\text { dos filhos. }\end{array}$ \\
\hline Excluídos do interior (EI) & Modos de exclusão. \\
\hline Ethos de classe (EC) & Expectativas em relação ao futuro dos filhos e seus sonhos. \\
\hline Dom social versus Dom natural DS & $\begin{array}{l}\text { Como as famílias lidam com o sucesso e o insucesso de seus } \\
\text { filhos. }\end{array}$ \\
\hline Capital Global (CG) & $\begin{array}{l}\text { Como que as famílias compreendem a escola: direito ou } \\
\text { privilégio. }\end{array}$ \\
\hline
\end{tabular}

Fonte: Os autores, 2020.

Na próxima seção, apresentamos a análise de falas e expressões das famílias nas entrevistas, explicitando ao final, a partir do Quadro 1, a correspondência dos conceitos bourdieusianos e as 
expressões dos entrevistados. Além disso, no início da seção, apresentamos os dados coletados em 2019, que explicitam a situação escolar no início do ano dos alunos cujas famílias foram entrevistadas e, desta forma, corroboram para sustentar nossas análises e conclusões.

\section{RESULTADOS}

No início de 2019 entramos em contato com a escola, solicitando informações sobre os alunos cujas famílias foram entrevistadas. Após consultar os registros escolares desses alunos, a escola informou que: i) Ale abandonou os estudos em 2019, depois de ter sido reprovado na $1^{\text {a }}$ série do Ensino Médio (EM) em 2018. Considerando que em 2013 estava no $8^{\circ}$ ano, se seguisse os estudos sem ter reprovado, teria concluído o EM em 2017; ii) Clara foi reprovada em 2017 na $3^{\text {a }}$ série do EM, casou-se e foi morar no interior; iii) sobre os alunos do $9^{\circ}$ ano, Luan foi transferido em 2015 , quando cursava a $2^{\mathrm{a}}$ série do EM; e iv) Luci desistiu dos estudos em 2016, quando cursava a $2^{\mathrm{a}}$ série do EM. Quanto aos alunos que cursavam o $6^{\circ}$ ano em 2013, v) Paula cursava o $9^{\circ}$ ano em 2017, quando foi transferida; e vi) Daniel desistiu dos estudos no $8^{\circ}$ ano em 2017, mudando-se para outra cidade. Ambos deveriam estar cursando o EM em 2017.

Esses dados, quanto à situção escolar dos alunos das famílias entrevistadas, revelam que, à luz dos estudos bourdieusianos, bem como desta observação no campo educacional, uma classe social despossuída de herança cultural tem muita dificuldade de avançar nos estudos, ou seja, concluir o EM, considerando que nenhum dos alunos das famílias entrevistadas o concluiu.

Na sequência, a fim de orientar a apresentação dos dados coletados, as análises estão organizadas a partir de duas entrevistas realizadas: a de Benta, mãe de Ale; e de Marisa, avó de Clara. Reiteramos que os nomes são fictícios, garantindo, assim, a confidencialidade da identidade das entrevistadas.

\section{Entrevista de Benta, mãe de Ale}

Benta foi uma das indicadas pela escola em que os pibidianos atuavam para a entrevista, por ter um filho (Ale) de 14 anos que estudava na $8^{\text {a }}$ série (equivalente ao nono ano do EF atualmente). Mãe de sete filhos, dos quais cinco moravam com ela e mais dois netos. Em sua casa de três cômodos moravam, portanto, nove pessoas. Durante a conversa, Benta nos contou que, além de Ale, mais uma de suas filhas, que tinha 11 anos quando Benta foi entrevistada, estudava, mas como estava na $3^{a}$ série do EF, frequentava uma escola municipal próxima a sua residência ${ }^{3}$. A renda com que sustentava a casa era de um salário mínimo que recebia dos proventos do marido, que teve acidente vascular cerebral e estava acamado, e do Bolsa Família. Uma das filhas que morava com ela havia começado a trabalhar recentemente e passou a contribuir para pagar algumas despesas.

\footnotetext{
${ }^{3}$ No Paraná, o município oferta o ensino nas séries iniciais do Ensino Fundamental; e o estado, as séries finais e o Ensino Médio.
} 
Ao ser questionada se considerava importante que seus filhos estudassem, respondeu: "Eu acho mesmo. Meu Deus do céu, o que seria se não fosse o estudo! É difícil, mesmo estudando já está difícil, pense se não tivesse estudo".

A primeira frase denota o poder redentor que Benta deposita na escola, com uma frase decorada do discurso que enraizou e que a entoava como um mantra. Entretanto, o interessante é que nenhum de seus sete filhos estudou além da oitava série do EF. A filha que estava trabalhando estudou até a $5^{a}$ série do EF, e interrompeu os estudos porque precisava trabalhar. Segundo Benta, a dificuldade em estudar decorre do fato de que, antes, viviam nos matos. Apenas uma das filhas e um dos filhos completou a oitava série do EF.

Quanto às expectativas em relação ao futuro de Ale, Benta enfatiza que sempre o incentivou a estudar: "O Ale agora está na oitava série. E graças a Deus eu quero, assim, ver se ele engrena ali, fecha (essa expressão da entrevistada se refere a ele concluir o EF), e ele faz uma faculdade. É isso que eu penso. Falo pra ele sempre: você continua estudando, vai, porque tá difícil, assim, a situação para mim, porque, assim, a gente que é pobre, tá difícil. Então, se não estudar, daí, Deus me livre. Que pra ele que sonha em ter profissão, daí tem que estudar mesmo"4.

Perguntamos, então: “Que profissão ele quer ter?”

E a resposta nos surpreende: "Olha ele, assim, ele tem várias coisas na cabeça, assim, que quer. Ele quer ser jogador de futebol, sabe, ele sonha alto mesmo. E mais, eu falei pra ele que pra ele ter esse sonho, pra ele realizar, ele vai ter que estudar muito".

Bem, em nosso país, sabemos que não há qualquer exigência - além de habilidade com a bola e afinidade com o futebol - para se tornar um jogador. Isto significa que, se o que Ale pretendia ser era realmente jogador de futebol, deveria investir em outras atividades, buscando treinamento especializado na área; e a escola, nos padrões que a conhecemos, oferece muito pouco nesse contexto. Evidenciamos, mais uma vez, a ilusão da escola como salvadora e como possibilidade de oferecer oportunidade para que aqueles das camadas menos favorecidas possam ascender socialmente.

Quando questionada sobre o que costumava fazer nas horas de lazer, Benta revelou que via TV e gostava de ouvir rádio, o que gerou um diálogo muito interessante para nossa análise, que apresentamos nos excertos que seguem.

Benta: $A$ gente houve rádio, e ali fala muito sobre aula, lá fala muito da XXXX (fazendo menção a uma universidade particular da cidade).

Pibidianos: A senhora falou da universidade, é o que a senhora quer?

Benta: Ah, com certeza, né, é o sonho de todas as mães.

Pibidianos: Se a senhora tivesse oportunidade, até que série a senhora teria cursado?

Benta: Olha, se seu tivesse oportunidade, eu acho que eu ia fazer uma faculdade.

Pibidianos: Do que a senhora gostaria de fazer essa faculdade?

[... Pausa longa para pensar]

4 Optamos por preservar a linguagem das entrevistadas, uma vez que representa sua realidade cultural. 
Benta: Agora, assim, né, se fosse assim, de várias coisas eu ia fazer, porque, assim, a gente assiste TV e a gente vê a pessoa indo além. E eu tenho assim... tenho o mesmo sonho, assim como se diz: criar asas e voar! Mas a gente não tem, né, não pode.

Pibidianos: Mas a senhora ia querer fazer o quê? Alguma coisa para trabalhar com pessoas?

Benta: Eu, assim, vamos dizer, como é que eu digo, assim, para fazer engenharia. Porque assim, eu tenho um sonho, assim, principalmente ir além, principalmente engenharia. É o meu sonho. Mas eu sei que eu não realizo esse sonho, talvez, quem sabe os meus filhos...

As ponderações de Benta corroboram as colocações de Bourdieu (2003a) de que, em geral, quando a população da camada menos favorecida tem que tomar alguma atitude em relação ao futuro, situa seu desejo muito abaixo ou muito aquém de suas possibilidades. Observamos, no diálogo, que Benta demora a responder que seu sonho era fazer engenharia. Quanto a isso, podemos inferir ao menos duas possibilidades: que ela nunca antes tenha pensado nessa possibilidade e, portanto, não sabia responder; ou, que realmente era seu desejo, mas se sentia constrangida em revelá-lo por considerar algo muito além de suas possibilidades, impossível de ser alcançado. Evidenciamos também, na fala de Benta, a expectativa que os pais depositam nos filhos, de que eles alcancem feitos que os pais não conseguiram e que, na realidade, segundo Bourdieu (2003a), sabem que os filhos também muito dificilmente conseguirão. Isso se revela no talvez expresso por Benta, ao expor o desejo de que o filho realize seu sonho, ou quando expressa que é o sonho de toda mãe que os filhos cheguem à universidade. Nesse contexto, interpretamos que o sonho expressa algo que sabemos que dificilmente será concretizado, porque ela não diz que é o que toda mãe deseja para seu filho, ou espera para seu fiho, por exemplo, mas reitera, inúmeras vezes, ser um sonho.

Quando questionada se outra pessoa da família gostaria de continuar estudando, Benta referese a outra filha, que diz que queria muito fazer uma faculdade, mas que não tinha condições de pagar. Além disso, ela argumenta que também precisava da ajuda dessa filha nas tarefas da casa, porque muitas vezes necessitava acompanhar o marido em consultas e era necessário alguém para cuidar dos netos e filhos menores. Falamos que existe uma universidade pública na cidade, que os cursos são à noite e, dessa forma, ela poderia fazer um curso superior gratuito nela, e que durante o dia poderia continuar ajudando a mãe. Ela concordou apenas balançando a cabeça, mas com o olhar e feição nada confiantes, e rapidamente referiu-se a outra filha: "E a XXXXX, também né. É que ela, assim, ela sempre foi uma aluna exemplar, ela nunca tirou nota ruim, e ela chegou à oitava série, fechou a oitava série, pegou o diploma. Então, eu tenho certeza que se ela chegasse numa faculdade, também ela ia ser uma aluna exemplar".

Desta forma, aparenta julgar que, se uma filha pudesse estudar, estaria sendo privilegiada em relação a outra filha, que também havia concluído o EF.

\section{Entrevista de Marisa, avó de Clara}

Dona Marisa, outra entrevistada, morava com mais três pessoas, sendo a neta que estudava na escola em que os pibidianos atuavam e dois filhos que já haviam abandonado os estudos há certo tempo. Os dois filhos trabalhavam sem registro em carteira profissional, eram autônomos e raramente 
conseguiam ajudar na renda familiar. Essa senhora não era aposentada e sua única renda era o Bolsa Família. Clara, criada como filha desde o nascimento, não trabalhava e só estudava. Isso porque, segundo sua avó, é preciso estudar para melhorar de vida. Para nossa entrevistada: "eu não sei ler, mas ela tem que aprender para ser pessoa na vida”. Dona Marisa, na sua simplicidade, compreendia que fazer escola, ler e escrever, é tudo na vida e que, por essa via, do estudo, o mundo se modifica, e a vida se torna mais realizável. Cabe considerar que, segundo ela, há diferença entre realização e felicidade, porque ela disse que era feliz, pois tinha um teto para chamar de casa, mesmo assim não se sentia realizada. A realização, para ela, tem a ver com a ascensão social, crescer na vida, isto é, emprego para os filhos, formatura para sua neta. Se tivesse estudado, disse nossa entrevistada, "a vida seria diferente, mas tive que trabalhar desde cedo para ajudar os meus pais". Contudo, com a sua Clara seria diferente. Disse ela: "vai estudar para ser gente no mundo".

Percebemos que havia, na entrevistada, um encantamento para com a escola e sua condição de propiciar ascensão nas questões sociais e econômicas. Para Dona Marisa, a educação é uma ferramenta importante para as classes trabalhadoras. Por ela, pela educação, o homem toma consciência de que faz a história, modifica suas circunstâncias, como senhor de si, bem como de sua própria história. De acordo com Marx (2011, p. 25), na obra o 18 brumário de Luís Bonaparte, "os homens fazem a sua própria história, contudo, não a fazem de livre e espontânea vontade, pois não são eles quem escolhem as circunstâncias sob as quais ela é feita, mas estas lhes foram transmitidas assim como se encontram". Por isso, no entendimento marxiano, se os homens soubessem disso, de que são fazedores da história, os oprimidos fariam uma nova história, sem opressão; fariam uma história de homens livres.

Todavia, é perceptível, na fala de Dona Marisa, demasiada crença na escola como lugar neutro, espaço democrático e, dentre outras coisas, promotora de ascensão social e, ainda, sem qualquer distinção entre educação e escola. De acordo com ela, era preciso que sua neta tivesse vontade de estudar e que quisesse estudar, conforme revela sua fala: "caprichando nos estudos, aprende; tendo vontade de aprender, aprende - só depende dela”. Nesse sentido, a escola é, no entendimento de Dona Marisa, o lugar de mudanças e de oportunidades para todos os indivíduos, independentemente de sua classe social. Mas é preciso, segundo ela, "vontade de aprender e de querer aprender". Ouvindo Dona Marisa fica perceptível que a escola, no seu entendimento, é capaz de resolver qualquer problema de ordem social e econômica: basta participar da escola e desejar estudar profundamente, "daí", disse ela, "a vida se resolve, mas se não querer estudar, vai ficar sempre assim". Cabe considerar que, mesmo se colocando como uma pessoa feliz, se sua neta não estudasse, a vida se repetiria, ou seja, aquela sua realidade se perpetuaria, e a única saída era, sem dúvida, como esperança redentora social, a escola. Para Dona Marisa, como dito anteriormente, "depende dela, somente dela".

Esta concepção de escola de Dona Marisa nos remete a Bourdieu, para quem o fracassado, aquele que não acompanha os estudos, ou seja, que não se realiza como possuidor de dons naturais, acredita ser responsável pelo seu fracasso. A culpa é exclusivamente dele, porque teve oportunidade de frequentar a escola, mas lhe faltaram força, determinação e vontade. Sua neta, disse ela, "pode ser o que quiser, só depende dela, mas se não se esforçar e caprichar, não vai chegar a lugar nenhum”. 
Essa leitura, o poder do querer, torna o sujeito vitorioso ou fracassado e, para o fracassado, a responsabilidade de eximir o verdadeiro culpado - a escola que, "conferindo uma sanção que se pretende neutra, e que é altamente reconhecida como tal, a aptidões socialmente condicionadas que trata como desigualdades de 'dons' ou de mérito, ela transforma as desigualdades de fato em desigualdades de direito" (BOURDIEU, 2014, p. 65, grifo do autor).

Nas falas de Dona Marisa ficou evidente que a responsabilidade de sua neta era vencer na vida, e que isso só dependia dela, dos seus esforços e suas vontades, porque a oportunidade estava dada, havia escola e tempo disponível para isso. Ao contrário do tempo dela, quando ainda adolescente, em que não estudou porque the faltava escola, bem como tempo para estudar. Isto porque, disse ela, "não estudei porque tive que trabalhar para ajudar os meus pais", e nesse sentido, sua neta podia e devia. É certo que o discurso de Dona Marisa não era exclusivamente seu e não representava sua realidade cotidiana, mas nascia de vozes ideológicas que, segundo Mészáros (2010), são orquestradas pelo sistema capitalista. Nas palavras desse autor, "aqui a questão crucial, sob o domínio do capital, é assegurar que cada indivíduo adote como suas próprias as metas de reprodução objetivamente possíveis do sistema" (MÉSZÁROS, 2010, p. 44).

É certo que nossa entrevistada lutava para viver a vida de todo dia, mas deixava escapar lutas ideológicas que iam definindo o seu cotidiano, construindo discursos e engendrando sua forma de pensar e de ser. Sua neta, menos esperançosa, envolvida nesse espaço de tensão, sabia que a sala de aula opera com um mundo que pouco se parecia com sua realidade familiar. Em uma perspectiva bourdieusiana, a herança cultural pouco se conecta com o habitus escolar e, por isso, as motivações de Dona Marisa, pautadas em esperanças ideológicas, diferiam de suas motivações. Na sala de aula, no arbítrio cultural, sua neta era violentada simbolicamente e, por isso, ela, diferentemente de sua avó, compreendia o fosso que se faz ver entre vontade e realidade, sonho e esperança. Esse fosso impediu que concluísse o EM, contradizendo os ditos de sua avó, tendo abandonado os estudos em 2017, quando reprovou na $3^{\mathrm{a}}$ série do EM. Assim, observamos que, apesar dos esforços e conselhos da avó, a disponibilidade e possibillidade de frequentar a escola não foram suficientes para que concluísse o EM.

No Quadro 2, explicitamos a correspondência entre o discurso dos entrevistados e os conceitos bourdieusianos.

\section{Quadro 2 - CORRESPONDÊNCIA ENTRE OS CB E AS ENTREVISTAS}

\begin{tabular}{|l|cl|}
\hline CB & CC \\
\hline HC & $\checkmark$ & Declarou que não conseguia ajudar os filhos nas tarefas escolares porque eles \\
& sabiam mais que ela, o que denota que, para ela, os filhos eram melhores. Ale \\
& abandonou a escola no $1^{\circ}$ ano do EM, depois de ter sido reprovado. \\
& $\checkmark$ & Avó analfabeta e, por isso, não conseguia acompanhar o desempenho da neta \\
& para saber se ela cumpria com os deveres escolares. Clara, depois de ter sido \\
& reprovada na $3^{\text {a }}$ série do EM, abandonou os estudos. \\
\hline
\end{tabular}




\begin{tabular}{|c|c|c|}
\hline & $\checkmark$ & $\begin{array}{l}\text { Mãe e pai adotivos apenas alfabetizados. } \\
\text { Pais catadores estudaram até o terceiro ano do EF, e não conseguiam ajudar o } \\
\text { filho nas tarefas escolares. } \\
\text { Irmão preso por porte de drogas, apenas o pai concluiu o EM. } \\
\text { Mãe concluiu o EF, o pai iniciou o EM. }\end{array}$ \\
\hline El & $\begin{array}{l}\checkmark \\
\checkmark\end{array}$ & $\begin{array}{l}\text { Sonho do filho era ser jogador de futebol e a mãe o incentiva, supondo que, } \\
\text { para alcançar o sonho, deveria estudar. } \\
\text { Avó desejava que a neta concluísse os estudos, porque os filhos não estudaram } \\
\text { por não terem tido condições para isso. } \\
\text { Desejava que o filho adotivo concluísse os estudos. } \\
\text { Principal conselho aos filhos era que não faltassem aula, porque, para } \\
\text { conseguirem trabalho, precisariam de muito estudo. } \\
\text { Aconselhava que o filho continuasse estudando para aprender o caminho } \\
\text { correto e não se envolver com drogas. } \\
\text { Considerava que o único meio de os filhos possuírem um emprego mais digno e } \\
\text { com melhor remuneração é estudando. Orientava seus filhos a não desistirem } \\
\text { da escola. Também acreditava que, através dos estudos, seus filhos seriam } \\
\text { mais respeitados. }\end{array}$ \\
\hline$E C$ & $\begin{array}{l}\checkmark \\
\checkmark \\
\checkmark \\
\checkmark\end{array}$ & $\begin{array}{l}\text { Depositava, na escola, a esperança de o filho se tornar um jogador de futebol. } \\
\text { A escola se configurava como a única forma de realização. } \\
\text { Depositava, na escola, a esperança de um futuro melhor para o filho. } \\
\text { Torciam pelos filhos e agradeciam a oportunidade que estavam tendo de } \\
\text { estudar, porque foi algo que não tiveram. Acreditavam que chegaria um tempo } \\
\text { em que seria necessário ter estudo para tudo. } \\
\text { Considerava que, para os filhos conseguirem seu próprio emprego e terem } \\
\text { condições de se sustentar sozinhos, precisavam estudar muito. } \\
\text { Relatou que o filho deveria estudar para trabalhar em escritório, para arrumar } \\
\text { um bom emprego. }\end{array}$ \\
\hline DSx & $\begin{array}{l}\checkmark \\
\checkmark\end{array}$ & $\begin{array}{l}\text { Atribuiu para si e para sua condição social o insucesso escolar dos demais } \\
\text { filhos que abandonaram os estudos, relacionado ao fato de que moravam no } \\
\text { interior e à necessidade de os filhos terem que trabalhar para ajudar no } \\
\text { sustento da casa. } \\
\text { O sucesso na escola dependia exclusivamente da neta. } \\
\text { Considerava que o filho adotado poderia ter melhores condições que os demais } \\
\text { já casados, se frequentasse a escola. } \\
\text { Acreditava que há mais oportunidades para estudar, mas, por outro lado, mais } \\
\text { chances de se envolver com drogas. Atribuiu ao filho a responsabilidade pelo } \\
\text { sucesso ou insucesso escolar. } \\
\text { Gostaria que os filhos aprendessem o que nunca teve oportunidade na vida. }\end{array}$ \\
\hline CG & $\checkmark$ & Escola como privilégio, porque precisavam de um grande esforço para que \\
\hline
\end{tabular}




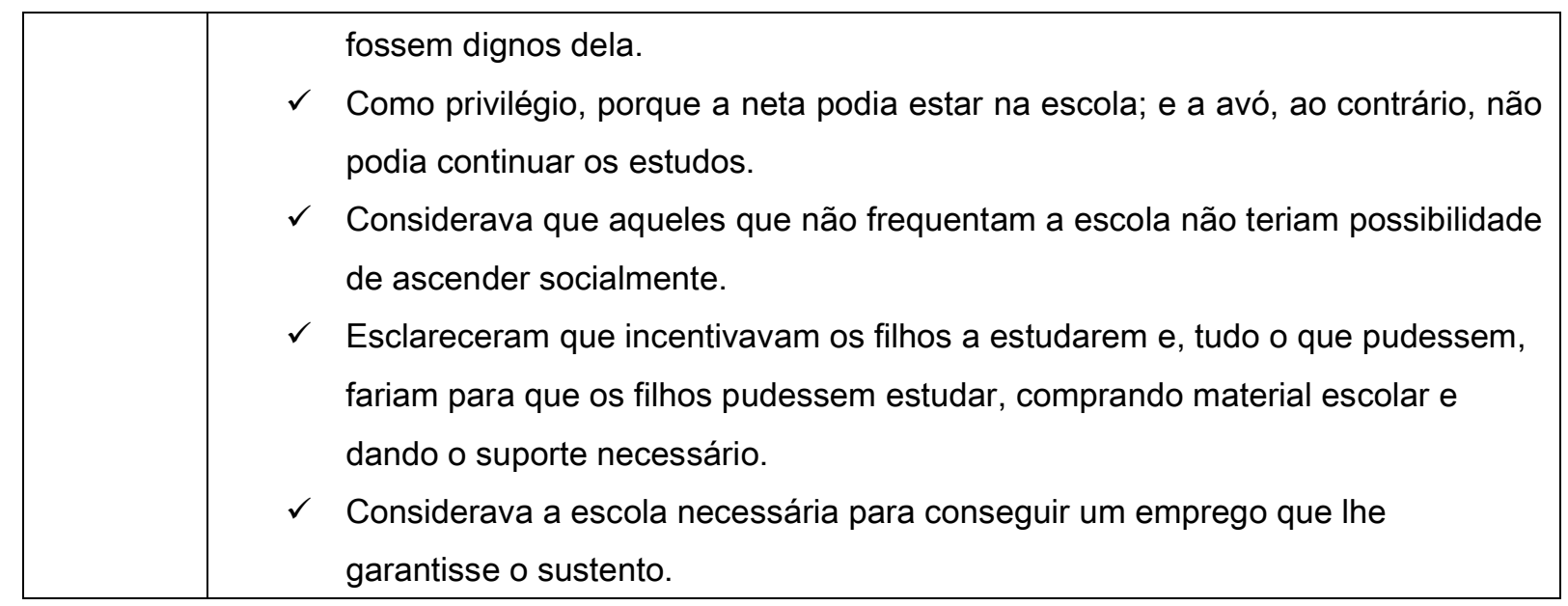

Fonte: Os autores, 2020.

Na seção subsequente, mesclando as duas entrevistas e a correspondência entre os conceitos bourdieusianos das seis entrevistas, enunciamos as conclusões do trabalho, a partir dos quadros 1 e 2 .

\section{CONCLUSÃO}

Faz-se necessário considerarmos que nossa pesquisa adotou, como quadro teórico, os escritos de Bourdieu sobre educação. Focamos em conceitos que são capitais de sua sociologia da educação para, a partir disso, verificar a importância, bem como a validade do seu pensamento em um determinado contexto específico. Utilizamos, em nossa análise, as expressões das famílias, que nos permitiram compreender a conexão que há, de algum modo, das notas de pesquisa de Bourdieu para com a realidade observada. Ainda que as observações bourdieusianas se reportem a contextos específicos, em algum grau, seu expediente teórico reflete a realidade aqui observada, uma comunidade periférica.

Desse modo, o principal resultado de nossa pesquisa evidencia-se pela crença que os entrevistados depositam na escola como lugar de privilégio. Entretanto, em uma perspectiva bourdieusiana, esse lugar de libertação, escola libertária, não passa de um lugar conservador. Nas palavras de Bourdieu (2014, p. 45), "tudo tende a mostrar que ele é um dos fatores mais eficazes de conservação social, [...] sanciona a herança cultural e o dom social tratado como dom natural".

As famílias entrevistadas tinham consciência de suas condições sociais e econômicas e, por isso, a escola se apresentava como uma espécie de aposta futura. Desse modo, para os entrevistados, os que puderem ir à escola, devem assim fazer. Percebemos uma espécie de hierarquia nos espaços observados, determinada pelo fato de uns se sobressaírem nos estudos, enquanto outros não conseguiam avançar na escola. Em outras palavras, não nasceram para isso. Os bons, na perspectiva das famílias entrevistadas, poderiam qualquer coisa, pois estavam estudando. A leitura que se faz da escola é, quase sempre, de neutralidade e de asseguramento de direitos, sobretudo na sociedade atual, nas esferas sociais e econômicas. Observamos que nossos entrevistados buscavam, na escola, elementos que pudessem melhorar a vida de seus filhos e, consequentemente, as suas próprias. Essa concepção de escola é, no entendimento de Mészáros (2010), a escola que forma para o modelo 
capitalista, ou seja, estabelece relações de imbricação entre escola e trabalho, trabalho e desenvolvimento social. Nas palavras desse autor, "aqui a questão crucial, sob o domínio do capital, é assegurar que cada indivíduo adote como suas próprias as metas de reprodução objetivamente possíveis do sistema" (MÉSZÁROS, 2010, p. 44). Pois bem, tanto a senhora Benta quanto a senhora Marisa atinaram para esse fim: formar os filhos para que pudessem trabalhar, mais precisamente, para vencerem na vida. Dona Benta, na sua ingenuidade, declarou que seu filho estudava para ser jogador de futebol e que, para realizar seu sonho - de ser jogador profissional de futebol - deveria estudar e muito. Percebemos, durante toda a entrevista, que a escola era esse lugar privilegiado e que, por meio dela, se poderia fazer qualquer coisa, inclusive ser jogador de futebol.

A cultura global da família está, segundo Bourdieu (2014), intimamente ligada com o êxito escolar. No caso de Dona Benta, a formação cultural da família permitia compreender a escola como espaço de redenção, isto é, ascensão social e econômica. Esse entendimento é deslocado da realidade, mas o deslocamento se faz em razão do capital global da família. Percebemos que nossas entrevistadas estabeleciam um fosso entre sua realidade e a realidade escolar, porque a escola era, para elas, um sonho distante, mas possível para seus filhos e netos. Por isso insistiam que eles, seus filhos e netos, poderiam vencer na vida, caso frequentassem a escola.

Todavia, cabe considerar que, quando perguntadas sobre os estudos, as respostas eram direcionadas para conclusão do EF e EM, nunca do Ensino Superior, o qual era, segundo elas, um sonho impossível, em razão de suas condições sociais. Nesse sentido, o ethos de classe outorga a dimensão do possível, fraturando o que é possível do impossível para seus descendentes. Nas palavras de Bourdieu (2014, p. 52), "as mesmas condições objetivas que definem as atitudes dos pais e dominam as escolhas importantes da carreira escolar regem também a atitude das crianças diante dessas mesmas escolhas e, consequentemente, toda sua atitude com relação à escola”. Com isso, diante da argumentação de Bourdieu, certamente a universidade não fazia parte de sua realidade, do habitus familiar de Dona Benta e de dona Marisa. Para Bourdieu (2012), existe uma exteriorização da interioridade, significando que o indivíduo, agente socializado, aqui pensado como membro de um grupo social, constitui-se na história a partir das relações que são estabelecidas ao longo de sua trajetória.

Frente às leituras bourdieusianas, bem como às expressões de Dona Benta e de Dona Marisa, às considerações das demais famílias entrevistadas e sua relação com os conceitos bourdieusianos, concluímos que a escola é um instrumento social complexo. Por um lado, porque serve como alavanca que movimenta esperança e sonhos, sobretudo dos mais necessitados. Isso se percebe com muita clareza nas entrevistadas, para quem a escola se constitui como espaço de redenção, de mudança de vida, lugar que oportuniza, para seus filhos, a realização de sonhos. Decerto que esse sentimento é bastante utópico, especialmente no contexto das leituras aqui efetivadas, mas que não deixa de acomodar utopias e fazer acreditar em uma vida melhor. Por outro lado, nos escombros das utopias reside a reprodução dessa estrutura entre vencedores e vencidos, ou seja, em uma perspectiva bourdieusiana, herdeiros e não herdeiros do sucesso humano. Vimos, na prática, como as pessoas se responsabilizaram por sua condição: nossas entrevistadas aceitavam suas condições de vulnerabilidade social, especialmente porque não estudaram e, disseram elas, "estamos assim porque 
não estudamos, mas se os nossos filhos estudarem, vão viver de forma diferente, vão ser gente na vida".

O interessante é que alguns dos filhos das famílias entrevistadas começaram os estudos, mas desistiram e, para elas, os que abandonaram a escola não nasceram para isso, ou seja, não tinham dons para o estudo. Elas desconhecem que não existe, segundo Bourdieu (2014), dom natural, mas social, e que a dificuldade nos estudos se fazia, dentre outras coisas, em razão da herança de cultura.

Nesse sentido, como dito anteriormente, nossas conclusões não são fatalistas, mas abeiram-se do pensamento de Bourdieu (2014), de que o sistema de ensino, aberto a todos, mas reservado a alguns, por meio da falsa ideia de democratização, reproduz e legitima uma ordem social, bem como gera uma falsa esperança de que, por meio da escola, se pode ascender socialmente e economicamente, como pudemos verificar a partir das entrevistas realizadas. Também verificamos, no ano de 2019 , quando retornamos à escola, que os alunos observados nessa realidade de pesquisa não conseguiram concluir os seus estudos. Eles frustraram os sonhos de seus familiares, como de dona Benta e de dona Marisa, que acreditavam na possibilidade de uma vida melhor, sobretudo em razão da caminhada escolar. Decerto que a responsabilidade por esta frustração acaba direcionada para os desafortunados do capital necessário para frequentar e usufruir com êxito da instituição escolar, na medida em que os resultados das avaliações escolares são tomados como parâmetros de análise da atuação e do espaço da escola dentro da estrutura social e das correlações nas quais a escola aparece como central. Os critérios seletivos adotados pela instituição escolar, por sua vez, não são estabelecidos de maneira aleatória, mas atendem aos interesses e ao arbitrário cultural específico, em que, seja pelos sistemas avaliativos, seja pela estrutura legitimada da prática pedagógica desenvolvida cotidianamente, torna explícita a lógica da conservação e da manutenção dos privilégios e, consequentemente, da estrutura social.

À luz do debate realizado, compreendemos a complexidade da escola, especialmente em determinados momentos, em relação ao discurso de mobilidade social, em que as famílias mais humildes acabam, no primeiro momento, apostando na escola como redentora de sua condição social e, posteriormente, percebem, a duras penas, que não dispõem dos instrumentos necessários para alavancar social e economicamente. Nesse contexto, assumem que não nasceram para isso, não são capazes de permanecer e concluir seus estudos. Por isso, em razão dessa complexidade que entorna a escola, é urgente a demanda de pesquisas que explicitem o papel da escola na sociedade contemporânea, que possibilitarão conhecer o ambiente e a realidade de alguns dos alunos.

\section{REFERÊNCIAS}

1. BOURDIEU, Pierre. A escola conservadora. IN: In: NOGUEIRA, Maria Alice; CATANI, Afrânio (Orgs.). Escritos de Educação. Petrópolis, RJ: Vozes, 2003a. p. 41-64.

2. BOURDIEU, Pierre. CHAMPAGNE, Patrick. Os excluídos do interior. IN: In: NOGUEIRA, Maria Alice; CATANI, Afrânio. (Orgs.). Escritos de Educação. Petrópolis, RJ: Vozes, 2003b. p. 217-227. 
3. BOURDIEU, Pierre; PASSERON, J-C. A reprodução: elementos para uma teoria do sistema de ensino. Rio de Janeiro: F. Alves, 1975.

4. BOURDIEU, Pierre. Escritos de Educação. Petrópolis - RJ, Vozes, 2014.

5. BOURDIEU, Pierre. O Poder Simbólico. Rio de Janeiro, 2012.

6. FREIRE, Paulo. Pedagogia da autonomia: saberes necessários à prática educativa. São Paulo: Paz e Terra, 1996.

7. GIL, Antônio Carlos. Métodos e Técnicas de Pesquisa Social. São Paulo: Editoria Atlas, 2010.

8. MARX, Karl. O 18 brumário de Luís Bonaparte. São Paulo: Boitempo Editorial, 2011.

9. MÉSZÁROS, Ivan. A Educação para Além do Capital. São Paulo: Boitempo Editorial, 2010.

\section{Maria Ivete Basniak}

Doutora em Educação pela Universidade Federal do Paraná (2014), Mestre em Métodos Numéricos em Engenharia pela Universidade Estadual do Paraná (2009). Realizou estágio pós-doutoral no Programa de Pós-Graduação em Ensino de Ciência e Tecnologia da Universidade Tecnológica Federal do Paraná. Atuou na Educação Básica (Educação Infantil, Anos Finais do Ensino Fundamental e Médio), na Educação de Jovens e Adultos, Educação Profissional e formação continuada de professores em tecnologias na educação como coordenadora pedagógica da Coordenação Regional de Tecnologia na Educação. Atualmente é professora Adjunta do Colegiado de Matemática e docente permanente do Programa de Pós-Graduação em Educação Matemática - PRPGEM da Universidade Estadual do Paraná, campus de União da Vitória. e líder do Grupo de Pesquisa GEPTEMatE - Grupo de Estudos sobre Prática e Tecnologia na Educação Matemática e Estatística. E-mail: maria.basniak@unespar.edu.br

\section{Antonio Charles Santiago de Almeida}

Doutor em Educação pela Universidade Federal do Paraná (2015), Mestre em Ciências Sociais pela Pontifícia Universidade Católica de São Paulo (2009), Graduado em Filosofia pela Universidade Estadual de Santa Cruz - UESC (2004). É professor do Programa de Mestrado Profissional - PROFILO. E-mail: sandiabo@yahoo.com.br

\section{Como citar este documento:}


BASNIAK, Maria Ivete; SANTIAGO DE ALMEIDA, Antonio Charles. Se nossos filhos estudarem, serão gente na vida?. Reflexão e Ação, Santa Cruz do Sul, v. 28, n. 3, p. 50-65, ago. 2020. ISSN 1982-9949. Disponível em: <https://online.unisc.br/seer/index.php/reflex/article/view/14682>. Acesso em: doi:https://doi.org/10.17058/rea.v28i3.14682. 